\title{
Política e acção pública. Entre uma regulação centralizada e uma regulação multipolar
}

\author{
Maria Madalena Fontoura \\ Universidade de Lisboa, Portugal
}

\begin{abstract}
Resumo
Este texto situa-se no campo alargado da análise política e tem o propósito de contribuir para a compreensão do processo de construção e regulação das políticas públicas, dando conta da complexidade do processo que vai muito para além do momento da decisão, implicando diferentes instâncias e uma grande multiplicidade de actores. Constitui uma reflexão, construída a partir das análises, interrogações, comentários e críticas produzidas por diferentes autores, a partir de diferentes prismas, que incidiram sobre a política educativa portuguesa das últimas décadas, no que diz respeito à autonomia das escolas e aos efeitos observados na aplicação das medidas que a invocaram, particularmente no que se refere aos projectos, aqui considerados como instrumentos para resolver problemas e criar oportunidades na fronteira entre o social e o político. Representa ainda a oportunidade de mostrar a importância do tempo na construção e análise das políticas públicas.
\end{abstract}

\section{Palavras-chave}

Análise política; Acção pública; Politicas públicas; Autonomia das escolas; Projectos

\section{Introdução}

Grande parte da investigação sobre o sistema educativo português, depois do "25 de Abril de 1974", situa-se no campo da sociologia e da sociologia política. No final da década de 80 , e sobretudo nos anos 90, surgiram outras abordagens, centradas na análise política mais convencional 
e em perspectivas de carácter sócio-histórico com incidência na administração e na organização da escola.

O que caracteriza a análise das políticas públicas é esta dupla herança que Ihe faculta um olhar crítico sobre a coisa pública, sobre a acção da administração e das elites em geral e a vontade de integrar a dimensão política na análise das organizações governamentais: "élaborer et mettre en oeuvre des politiques publiques, c'est encore faire de la politique..." (Muller, in Van Haecht, 1988: 23).

O campo da acção pública é um campo vasto: abarca o que está antes da decisão, a elaboração das agendas a partir das expectativas e exigências da população, a antecipação e a gestão das mobilizações que os projectos suscitam; inclui a activação de redes de actores que constroem a configuração decisional, formal ou informal, e o desenvolvimento de fases sucessivas de um processo, feito de interdependências, em diferentes níveis institucionais.

Este texto privilegia não tanto os conteúdos das mudanças propostas pelas decisões governamentais e as medidas administrativas subsequentes, em ordem à sua execução, mas o seu significado, na perspectiva dos analistas e dos actores envolvidos na sua execução. Recorremos a um conjunto alargado de textos de análise e reflexão crítica, relativo às formas de relação entre o Estado e a educação (Stoer, Cortesão e Correia, 2001; Stoer e Magalhães, 2005) em tempo de recomposição do campo social e da organização escolar (Lima, 1995, 1999, 2002, 2004; Afonso, 1998; Lima e Afonso, 2002; Formosinho, Ferreira e Machado, 2000; Formosinho, Fernandes, Machado e Ferreira, 2005) e convocámos alguns estudos relativos à adopção e implementação dos projectos educativos de escola e às lógicas de acção dominantes (Costa, 1997; Fontoura, 2000, 2001, 2005; Sarmento, 2000), às modalidades de regulação (Barroso, 1999, 2000, 2003, 2006), às questões críticas do currículo (Morgado, 2000; Pacheco, 2002; Fontoura, 2006) e às relações entre os professores e o poder local que têm acompanhado as continuidades e descontinuidades inerentes à mudança de paradigma da acção pública em educação.

Para as questões associadas à transnacionalização da educação e à emergência de uma nova cultura política, recorremos a Nóvoa $(1998,2005)$, Nóvoa e Lawn (2002), Santos (1994, 2001, 2006) e Giddens (1995, 2004), 
particularmente no que se refere à incorporação da temporalidade na compreensão da agência humana. Para além dos autores supracitados, foram ainda importantes os trabalhos académicos que tenho orientado e arguido, na área de especialização em Administração Educacional. A recolha não foi exaustiva, poderíamos convocar outras informações, dispersas por diferentes livros e artigos, monografias, dissertações e teses não publicadas.

Para que não haja equívocos, convém precisar que entendemos política como um termo abrangente que pode ter várias acepções - a esfera política (polity), a actividade política (politics) e a acção pública (policies), segundo Muller e Surel (1998: 13). Neste artigo, o conceito de política pública é tomado numa perspectiva cognitiva, no sentido que lhe conferem Hall (1993) e Surel $(2004,1995)$, inspirados nos trabalhos de Thomas Kuhn (1983) sobre a revolução científica. Nesta perspectiva, as políticas públicas, geralmente apresentadas sob a forma de um programa de acção governamental num sector da sociedade ou num espaço geográfico (Mény e Thoening, 1989), são mais do que um processo de decisão em que participa um certo número de actores, elas constituem o lugar em que uma determinada sociedade constrói a sua relação com o mundo e, por isso, devem ser analisadas como processos através dos quais são elaboradas as representações com que a sociedade se dota para compreender o real e concebidos os instrumentos para agir sobre o real percebido. Trata-se de um processo cognitivo e um processo prescritivo.

Ao definir uma política pública como paradigma, Surel (1995) considera que, tal como um paradigma, uma política pública é constituída por quatro elementos fundamentais: princípios metafísicos gerais, hipóteses práticas, metodologias de acção e instrumentos específicos. Isto significa que uma política pública, tal como um paradigma, não aparece senão a partir da cristalização da matriz sectorial à volta dos seus quatro componentes e de um sistema de actores hierarquizado segundo a sua identificação com a matriz. Antes do aparecimento de uma política pública conflituam diferentes visões do mundo; trata-se, segundo Surel, de uma fase flutuante em que se podem observar certas iniciativas e mesmo tomar certas medidas legislativas mas, paradoxalmente, sem força de lei, pois enquanto os quatro elementos da matriz não se articularem, a aplicação das medidas tomadas acaba por ser travada entre os jogos e as lutas dos actores. Esta fase corresponde à fase 
de emergência dos problemas públicos, em que os actores dispõem de imagens contrastadas do problema a tratar e, por conseguinte, fazem opções diferentes e apresentam soluções, muitas vezes incompatíveis. É uma fase em que há uma grande abertura à entrada de novos participantes, atraídos por problemas precisos, relativamente limitados, para os quais têm soluções próprias, no âmbito de paradigmas diferentes. A crise só será resolvida à medida que se conseguir estabelecer algum acordo acerca das representações, normas, dispositivos e actores, para a resolução dos problemas num determinado quadro cognitivo, normativo, metodológico e instrumental. A adopção de um novo paradigma, ou a imposição de um novo paradigma pelos actores politico-administrativos, sempre se traduz na (re)distribuição do poder e na alteração das relações de força no seio do aparelho de Estado. A não resolução dos problemas, no quadro da matriz adoptada, significa que os métodos e os instrumentos adoptados não são os adequados e que continua a haver anomalias na relação entre o Estado e a Sociedade.

O enfraquecimento do Estado reduz a amplitude de uma visão monocentrada, hierarquizada da decisão pública, enquanto instrumento do Estado que determina e concebe os objectivos e as regras para a acção pública e, simultaneamente, fomenta a participação de um maior número de actores, no seio dos quais o Estado não é mais do que um dos partenaires. Isto significa o deslocamento de uma regulação centralizada para uma regulação multipolar, marcada pela multiplicação e a policentricidade dos níveis de acção com fortes interdependências entre numerosos e diferentes actores, com interesses divergentes, ou mesmo antagónicos (Commaille, 2004: 416).

As acções públicas são matrizes cognitivas e normativas (relativamente estáveis no tempo) constitutivas do universo cognitivo dos actores, no seio dos quais inscrevem as suas acções (Muller, 2004). Em termos de regulação, a acção pública organiza-se em torno de lógicas territoriais e lógicas sectoriais que se prendem a dialécticas sociais diferentes. A primeira refere-se a uma relação centro-periferia, a segunda remete-nos para uma dialéctica global-sectorial. No primeiro caso, entramos na área de acção de uma regulação institucional que evidencia as dimensões de coordenação, controlo e influência exercidas pelos detentores de uma 
autoridade legítima; no segundo caso, entramos na área de acção de uma regulação situacional, activa e autónoma (Barroso, 2006: 13), um processo activo de produção de "regras de jogo" que (re)orientam o funcionamento do sistema. Neste caso, a complexidade aumenta pois a matriz cognitiva global desloca-se do âmbito do Estado para outros âmbitos além do Estado, para redes de interesses económicos e financeiros, por exemplo, ficando o Estado com a função de traduzir num quadro territorial essa matriz. Isto significa que o lugar de construção dos quadros gerais de interpretação do mundo nem sempre coincide com os lugares de construção do compromisso social. Hoje, é legítimo admitir que a globalização e a europeização tendem a dissociá-los, dado que as decisões tomadas a nível mundial, tal como as decididas a nível europeu, restringem o espaço deliberativo e condicionam a eficácia das comunidades políticas nacionais.

Com este texto, pretendo, em primeiro lugar, mostrar que o Estado português tem actuado como um agente catalizador de energias modernizadoras, em grande parte por pressão de instâncias supranacionais, particularmente da UE, e tem espoletado um conjunto de medidas direccionadas para a revisão das relações - Estado-Sociedade Civil-Mercado - e a recomposição dos espaços de acção. Em segundo lugar, pretendo mostrar que as sucessivas medidas de reforma, ora de cariz neoliberal ora procedentes de outras perspectivas, mais ou menos conservadoras e mais ou menos democráticas, associadas à "descentralização", à "autonomia das escolas" e à "territorialização", são medidas, muitas vezes incompletas, para auscultar o tipo de recepção que a generalidade dos actores dá às decisões de gabinete. Tais medidas correspondem, apenas, ao início do processo de elaboração de políticas públicas. As políticas públicas são comparáveis a malhas de decisões, redes construídas através da relação com os indivíduos, grupos e organizações cuja situação afectam. Daí a exigência do tempo para o seu desenvolvimento e manifestação.

\section{Evolução do Estado: entre a legitimidade e a governa- bilidade}

De uma ou de outra forma, a crise do Estado-Providência está na origem da análise das políticas públicas. Especialmente a partir da década de 70, o contrato social, subjacente aos Estados democráticos europeus, foi 
fortemente questionado tanto por excluir grupos e questões sociais importantes (por exemplo, os imigrantes e a diversidade cultural) como por incluir outros grupos, subordinando-os a formas de inclusão destituidoras de poder, como é o caso das mulheres. A tensão entre os pilares do Estado moderno aumentou e os sinais do esgotamento do modelo políticoadministrativo, que serviu de referência ao desenvolvimento da sociedade no pós-guerra, foram-se evidenciando com nitidez.

A questão começa, portanto, por residir na perda de legitimidade. O ponto de viragem situa-se em 1975, quando a Comissão Trilateral publicou o seu relatório sobre a crise da democracia da autoria de Crozier, Hungtinton e Watanuki (1975) em que se afirma que as democracias estavam em crise porque se encontravam sobrecarregadas com direitos e reivindicações e porque o contrato social era demasiado inclusivo (Santos, 2006: 375). A partir desta análise e do poder social que a sustentou, a crise de legitimidade transformou-se em crise de governabilidade e rapidamente se disseminou a "terapia proposta pela Comissão Trilateral: do Estado central para a devolução/descentralização; do político para o técnico; da participação popular para sistemas de peritos; do público para o privado; do Estado para o mercado" (idem: 376). Segundo esta comissão, impunha-se reduzir o papel do Estado em áreas como a do bem-estar social e económico, da segurança e da identidade cultural, o que viria a ser imposto, à escala global, por acção do Consenso de Washington. Contudo,

o Estado fraco que emerge do Consenso de Washington, só é fraco ao nível das estratégias de hegemonia e de confiança. Ao nível da estratégia de acumulação é mais forte do que nunca na medida que passa a competir ao Estado gerir e legitimar no espaço nacional as exigências do capitalismo global. Não se trata pois da crise do Estado em geral mas de um certo tipo de Estado (Santos, 2006: 321).

Associada a este processo de crise, a pretensa inevitabilidade dos imperativos neoliberais tem vindo a afectar o âmbito e a forma do poder de regulação social do Estado com transformações que estão a configurar uma nova forma de organização política, mais vasta do que o Estado, "de que o Estado é o articulador e que integra um conjunto híbrido de fluxos, redes e organizações em que se combinam e interpenetram elementos estatais e não estatais, nacionais, locais e globais" (idem: 338). Nesta nova configuração política, a especificidade do Estado consiste em assegurar as regras do jogo entre interesses sectoriais. 
Para Beck (2000), é o próprio dinamismo da sociedade moderna que a está a modificar nas suas formações de classe, de status, de ocupação, nos papéis sexuais, na família nuclear, na indústria, nos sectores empresariais e, sub-repticiamente e de modo não planeado, a destruir os seus próprios fundamentos. A incerteza instala-se em todos os domínios e a política irrompe para além dos espaços formais, confrontando e reduzindo o poder central.

\section{Multiplicidade e diversidade dos actores e das instâncias de regulação}

Desde os finais dos anos 80 que novas organizações internacionais têm vindo a propor a sua visão para as políticas a seguir pelos diferentes Estados. Trata-se de instituições financeiras que incarnaram o consenso de Washington (FMI e Banco Mundial), mas também a OCDE e mais recentemente a União Europeia. A estratégia de Lisboa (2000) sobre a "sociedade do conhecimento" está na origem de uma mudança que levou à elaboração de um programa de trabalho "Educação \& Formação 2010" que abre um novo tempo para as políticas educativas europeias (Nóvoa, 2005). Depois de Lisboa, o Conselho Europeu toma duas decisões-chave: a definição de um novo objectivo estratégico "tornar a economia do conhecimento a mais competitiva e a mais dinâmica do mundo"; e a adopção de um novo método aberto de coordenação, em todos os níveis, "de modo a dirigir esta estratégia de forma mais coerente e a que os resultados obtidos sejam objecto de acompanhamento efectivo". O ano de 2000 está marcado pelo lançamento de dois documentos essenciais, que definem uma nova matriz de intervenção: o Memorandum sobre a educação e a formação ao longo da vida e o Relatório europeu sobre a qualidade da educação escolar que, conjuntamente, irão permitir à União Europeia agir como uma instância de avaliação e de regulação das políticas nacionais (cf. Nóvoa, 2005: 209). Lado a lado com a erosão gradual da "soberania nacional", numa série de domínios de políticas, foi crescendo a influência da União Europeia, em diferentes domínios, nomeadamente no campo da educação. Dir-se-ia que nas três últimas décadas se procedeu "à lenta gestação do processo de europeização que agora ensaia a maturidade" (Antunes, 2005: 130). 
A UE constitui um sistema político organizado em níveis distintos supranacionais, nacionais e subnacionais - que se estende por diferentes contextos, sobre os quais se exercem diferentes pressões. Organizada em níveis distintos, a União Europeia é regulada por um sólido aparelho jurídicolegal e outras formas de poder, tanto formais como informais, em que intervêm múltiplos actores. Redes de agentes responsáveis pela elaboração de políticas e agentes pertencentes a 'lóbis' configuram uma nova forma de autoridade supranacional, articulada num conjunto de instituições para assegurar que os Estados respeitem os compromissos assumidos, como uma forma de poder que fornece a lógica das interacções e uma forma de direito que fornece a linguagem das relações intra e interinstitucionais. Isto significa que é a cultura de governança que existe na UE, caracterizada pelas misturas entre público e privado, formal e informal, normal e extraordinário, que fornece a base para a evolução das formas de governança nos estados membros.

Contudo, para a apropriação das normas, definidas ao nível europeu, e sua incorporação na lógica dos discursos, das identidades, das estruturas políticas e das políticas públicas nacionais, é forçoso passar por processos de desinserção das relações sociais dos contextos locais de interacção (descontextualização) e de redefinição das relações sociais descontextualizadas (recontextualização) e de fixação de novas condições de espaço e de tempo (Giddens, 1995). A actividade social surge-nos sempre constituída através de três momentos de diferença entrecruzados temporalmente, paradigmaticamente e espacialmente. É um erro, afirma o autor, "supor que o conceito de acção pode ser plenamente elucidado fora do contexto dos modos de actividade historicamente localizadas" (Giddens, 2004: 15).

A apropriação das novas normas e a sua implementação, bem como o nível de cumprimento, varia consideravelmente, segundo as tradições, as políticas e as culturas. Localmente, as pessoas pensam em novos paradigmas e comunicam dentro das velhas formas e instituições. Há um compromisso múltiplo e contraditório que mistura diferentes lógicas, manifestando que ainda se mantêm as velhas categorias institucionais, apesar de já não serem vistas como eficazes. Isto significa que ao lado de uma legitimidade contestada temos a emergência de diferentes pólos de poder e de outras tantas formas de legitimação, em competição para conquistarem uma posição dominante. 
A construção de um sistema político supranacional (UE), com tudo aquilo que ela supõe, o desenho inicial da estrutura, a forma que foi desenvolvendo e a evolução para formas de soberania partilhada e complexas interdependências, tem, no entanto, um efeito desestruturador sobre os quadros (normativo e cognitivo) habituais, a ponto de modificar, pouco a pouco, o referencial dominante das políticas públicas (Surel, 1995). Actualmente, a UE molda e regula diversas áreas: os mercados, as tecnologias, os desenvolvimentos técnicos, o ambiente "e alguns aspectos dos serviços de providência, incluindo a saúde pública, questões relativas aos direitos de cidadania e alguns aspectos da política externa, particularmente as políticas comerciais e de transacções" (Burns e Carson, 2003: 181). A situação é complexa, pois, apesar da reconhecida importância da estruturação de uma ordem global, há grandes contrastes entre os problemas globais e os processos políticos que continuam a ser nacionais.

\section{Da governabilidade à governança: perspectivas e linhas de acção}

Aberto a todos os favorecimentos da liberalização, da mercantilização e da privatização, o Estado torna-se, então, um campo político em que as regras ligadas a diferentes visões do mundo se sucedem, sem atingirem a normalização, o que corresponde a um real enfraquecimento das estruturas de poder tradicionais, com efeitos ao nível da orientação, coordenação e controlo dos actores, transformando as organizações em 'arenas' políticas. É neste contexto que o conceito de governança emerge e se apresenta como um novo paradigma de regulação social (Jessop, 1998), uma nova maneira de governar, assente numa outra relação entre o Estado, a sociedade civil e o mercado, capaz de suplantar o paradigma anterior, assente no papel privilegiado do Estado, e de promover a articulação entre os diferentes tipos de regulação em cada unidade temporal.

Considerando paradigma um termo demasiado forte para caracterizar o fenómeno, Santos (2006: 371) prefere designá-lo por matriz regulatória do neoliberalismo, centrada na questão da governabilidade que tende a agravar a crise de legitimidade do Estado. Trata-se de uma estrutura basilar e, simultaneamente, de um ambiente fomentador de toda uma rede de ideias pragmáticas e de padrões de comportamento cooperativo, partilhados por 
actores e interesses seleccionados. Concretiza-se numa rede auto-activada, destinada a lidar com o caos, num contexto em que nem a ordem normativa, exercida do topo para a base (estatal), nem o ordenamento participativo autónomo, feito da base para o topo (democracia participativa), são desejáveis, ou estão disponíveis (Santos, 2006: 374). Mas não é a única. Há uma outra matriz de governação, gerada no seio dos movimentos sociais e das organizações da sociedade civil que vêm travando uma luta contra as formas de opressão, geradas ou intensificadas pela globalização neoliberal (idem: 384).

Segundo Burns e Carson (2003), na UE existe uma cultura de governança democrática que fornece os princípios organizadores particulares e regras do jogo que orientam o discurso, a negociação e a tomada de decisão em qualquer rede ou comunidade de políticas. Estes princípios divergem dos princípios da democracia formal e representativa; são democráticos, no sentido em que dão voz e legitimidade a um conjunto diversificado de actores, nas questões que afectam os seus interesses particulares. As instituições da UE têm envolvido, de forma crescente, um amplo conjunto de actores: grupos de interesses, privados e públicos, influem de diferentes formas na decisão, quer através de consultas formais quer agindo como fontes de conhecimento ou como mediadores. Esta multiplicidade de actores e de influências tem levado a um conjunto significativo de mudanças, nos vários níveis de acção, nomeadamente nas instâncias representativas locais que têm vindo a institucionalizar a 'participação', embora sem garantir uma participação efectiva no processo de decisão.

No vasto domínio das políticas públicas, tendo por referência Le Galés (2004), podemos distinguir diferentes usos do conceito de governança. Para os autores ligados à gestão pública, a questão da governança significa que há um problema de eficácia da acção pública a resolver e, por isso, somos remetidos para a formação de regras que permitam o jogo mais eficaz do mercado e dos actores e, assim, melhorar a eficácia das políticas públicas. Para os que têm uma perspectiva mais próxima da economia política, governança é entendida como a articulação estabilizada de diferentes tipos de regulação e é da combinação desses tipos de regulação que resultam os modos de governança dos sectores, dos territórios e da sociedade. Numa 
outra linha (Kooiman, 1993) considera-se a governança como um mecanismo de negociação, em que participam o público e o privado, capaz de resolver problemas e criar novas oportunidades sociais. Nesta perspectiva, insiste-se na capacidade da sociedade se auto-regular e na capacidade de resistir à autoridade do Estado. Em torno de Kooiman e dos autores inspirados pela sociologia das organizações e as redes de políticas públicas,

acentuam-se sobretudo as formas horizontais de interacção entre os actores, as interdependências, a regularidade e as regras de interacção e de troca, a autonomia dos sectores e das redes em relação ao Estado, a dimensão temporal, os processos de coordenação dos actores políticos e sociais e, por vezes, os constrangimentos associados à decisão (Le Galès, 2004: 247).

A governança é vista como um novo estilo de governo, caracterizado por um maior grau de cooperação e pela interacção entre o Estado e os actores não estatais. Newman (2005), referindo-se ao argumento de que, por acção das formas de coordenação desta governança, são substituídas as hierarquias e os mercados, enquanto modos de interacção dominantes (Kooiman, 1993), diz não encontrar, nesta coordenação, mais mudanças que continuidades. Para a autora, a matriz da governança desenvolve-se sobre o regime hierárquico, centrado no primado do administrador tradicional, que oferece orientações objectivas e neutrais e administra os recursos de acordo com regras burocráticas do governo central ou local e o regime de mercado que constrói uma imagem de gestor diferente - o gestor empreendedor. A matriz da governança desenvolve-se, de maneira um tanto inquietante, sobre estes dois regimes. E é entre as "forças do conservadorismo" e atitudes proactivas, entre a "falência" e o "sucesso" das organizações, entre o estaticismo e a transformação, entre as noções de um velho "uniforme" e uma gestão de ordem "diversa" que foram surgindo novos instrumentos e uma nova liderança, associando à exigência da participação a exigência de autoregulação, num contexto de construção da autonomia. Paradigma ou matriz, governança reúne uma série de axiomas e argumentos que articulam o sistema simbólico e o mundo concreto, conferindo ao sistema conceptual abstracto uma orientação lógica e racional, que configura a acção dos actores sociais. 


\section{As regras de jogo e os instrumentos}

É através da produção de novas regras de jogo (Reynaud, 1997) que se revêem critérios e disposições práticas que estruturam a actividade de um sistema de actores de forma coerente e durável. Esta acção estruturante implica a (re)distribuição do poder e significa "dominação" do(s) actor(es), que estão na origem dessa (re)estruturação e da sua consolidação. Tal não acontece apenas na confrontação entre instituições e grupos de cidadãos, mas também nos conflitos entre a política nacional e local, entre uma administração com motivações gerencialistas e gestores com motivações humanitárias ou ecologistas, entre perspectivas racionalistas e perspectivas construtivistas, e assim por diante. A regulação nunca é consensual, pelo que, na maior parte dos casos, só se consegue a partir de compromissos entre grupos ideológica ou politicamente diferentes, através de estratégias de negociação, nem sempre muito claras. Beck fala de "subpolítica, notando que a subpolítica está sempre à disposição do lado oposto ou do partido oponente para os seus propósitos contrários" (2000: 20).

A instalação das imagens, das leis, das regras e a sua articulação ao real concreto exige a utilização de estratégias de acção e instrumentos específicos. Os instrumentos - legislativos e regulamentares, económicos e fiscais, informativos e comunicacionais - são fundamentais para orientar as acções e as operações consideradas legítimas. Lascoumes e Le Galès (2004: 268) consideram

a instrumentação da acção pública um meio de orientar as relações entre a sociedade política (via executivo administrativo) e a sociedade civil (via sujeitos administrados) por intermediários, dispositivos misturando componentes técnicas (medida, calculo, leis e procedimentos) e sociais (representações e símbolos).

Conjuntos mais ou menos coordenados de regras, de normas e de procedimentos para governar as interacções e os comportamentos dos actores e das organizações, os instrumentos determinam, em parte, a maneira como os actores se vão comportar: os grupos e os interesses que vão privilegiar, os constrangimentos e incertezas que vão criar e as imagens que vão veicular. "Cada instrumento é uma forma condensada de governabilidade, quer dizer de um saber sobre o exercício do poder social" (Lascoumes, 2004). Uma vez adoptados, os instrumentos alimentam uma 
dinâmica de institucionalização e, simultaneamente, abrem para perspectivas de utilização não previstas, dificilmente controláveis. Sem defender a homogeneização, nem a uniformização, a paleta de instrumentos concebidos, no âmbito do programa Educação \& Formação 2010, visando uma aprendizagem mútua e o acompanhamento dos progressos realizados indicadores, critérios, níveis de referência, troca de boas práticas e outros impõe princípios e normas de regulação aos estados-membros. No campo da educação, o discurso europeu tende a impor-se como ideal regulador, definindo as "possibilidades" e as "impossibilidades" (Nóvoa, 2005).

\section{A governança vista à luz do caso português}

Com perspectivas e intencionalidades diferentes, a administração do pós 25 de Abril tem tomado medidas legislativas que pretendem romper com a lógica anterior, fortemente centralizada, mas nem sempre foi perceptível o rumo perseguido.

No quadro do $1^{\circ}$ regulamento jurídico da autonomia (Dec-Lei ํo 43/89, de 3 de Fevereiro), foi 'dada', a cada escola ( $2^{\circ}$ e $3^{\circ}$ ciclos do ensino básico e do ensino secundário), a possibilidade de usufruir de margens de autonomia. A partir dessa data e, em nome de uma legitimidade democrática, foram tomadas algumas medidas que articulam a autonomia, a descentralização e a territorialização: por um lado, a transferência de responsabilidades e competências administrativas para a escola e a estimulação da gestão participativa e do aprofundamento das relações com a comunidade; e, por outro lado, a transferência de responsabilidades materiais e competências administrativas para organismos regionais do Estado, apelando, em geral, à participação na tarefa educativa de diferentes entidades e à constituição de parcerias.

Em teoria, cada escola passou a ter a possibilidade de alargar o seu espaço de decisão e ensaiar formas distintas de gerir o tempo e o currículo; de gerir o crédito horário disponível para o exercício de cargos de gestão intermédia e criar e desenvolver projectos, entre outras iniciativas, de acordo com as especificidades das escolas, imaginação, militância, liderança, tradições. As margens de liberdade, porém, não foram suficientes para o aparecimento e consolidação de um projecto organizacional distinto e original. 
Num ambiente marcado por sucessivas mudanças e a entrada de novos actores, os níveis de incerteza tornam-se especialmente elevados e as situações críticas multiplicaram-se. Tais situações, associadas à globalização, à europeização e à disseminação de uma visão neoliberal, vieram a justificar a deslocação da orientação da política educativa portuguesa da esfera da democratização para a esfera da modernização, por meio de várias estratégias. Uma estratégia geral, de nível macro, legitimada pela necessidade de conectar um universo fragmentado e coordenar os actores, afastando posições demasiado políticas (legitimação democrática) e modelos corporativistas (legitimação profissional); estratégias de nível micro, animadas a partir do próprio aparelho político-administrativo, legitimadas pela necessidade de competências gestionárias para implementar as medidas decretadas, relativas ao funcionamento do sistema, nos seus mecanismos organizativos e na sua relação com o exterior.

Com $02^{\circ}$ Regime de Autonomia, Administração e Gestão dos Estabelecimentos da Educação Pré-Escolar e dos Ensinos Básico e Secundário (Dec.-Lei nำ115-A/98), construído a partir da ideia de partilha e a complementaridade de responsabilidades entre o Estado e a Sociedade, passa a reconhecer-se à escola autonomia em diferentes domínios, bem como a possibilidade de a aprofundar e de obter um contrato de autonomia, celebrado entre a escola, o Ministério da Educação, a administração municipal e outros parceiros, eventualmente interessados. Na perspectiva de vários analistas, com este regulamento e a pretexto de responder à complexificação crescente do sistema, por efeito de medidas como, por exemplo, as relativas aos Territórios Educativos de Intervenção (Despacho no 147 - B/96 de 1 de Agosto) ou aos Currículos Alternativos (Despacho oㅡ22/SEEl/96), passou-se para um regime mais centralizado e mais prescritivo. Procurando reduzir a complexidade e minimizar os efeitos das novas prescrições, nas escolas, tudo, ou quase tudo, se vai reduzindo ao possível. Assim aconteceu com os Currículos Alternativos, que cedo se converteram em dispositivos de diferenciação de turmas (Fontoura, 2005), mais e menos problemáticas, segundo as velhas lógicas institucionais e, mais e menos capazes, segundo as novas exigências do mercado. E assim está a acontecer em muitas escolas com os Projectos Curriculares de Escola e de Turma (Decreto- Lei no 6/2001 de 18 de Janeiro), os instrumentos que o executivo proporcionou às escolas 
e aos professores para adequação do currículo às características e aos percursos dos alunos, aos recursos e aos fins dos respectivos projectos educativos, apesar dos regulamentos, dos critérios de referência, das 'boas práticas', dos inspectores e dos instrumentos operativos e avaliativos que foram configurando as disposições e os procedimentos dos actores (Fontoura, op., cit.). O que é afinal um projecto curricular de escola? A resposta é difícil de dar quando professores e alunos são confrontados com decisões curriculares oriundas da administração central que, na prática, traduzem um conceito de currículo como um plano de execução prédeterminado (Pacheco e Morgado, 2002).

A partir do $2^{\circ}$ Regime de Autonomia (Dec.-Lei nº115-A/98) há uma abertura formal à participação dos pais e à entrada de novos parceiros mas, em muitos casos, os eleitos para os órgãos de gestão e mesmo para as associações de pais são os "pais-professores" que permanecem ligados a lógicas corporativas; há projectos educativos e projectos curriculares de escola mas, na maior parte dos casos, os professores organizam-se em volta de problemas relativamente limitados que implicam directamente os seus alunos; há departamentos curriculares em que se associam diferentes disciplinas mas, na maior parte dos casos, o seu funcionamento é monodisciplinar. Neste cenário, os operadores, habitualmente definidos como street level bureaucratics ("burocratas de bairro"), que actuam em contacto directo com a população alvo dessas medidas, gozam de uma discrecionaridade considerável (Pasquino, 2005).

Segundo Lima (1999: 65), a governação democrática das escolas e 0 benefício de usufruir de uma autonomia acrescida e legitimada cedo se revelaram ilusórios. Quanto muito terão robustecido os "burocratas de bairro". Dentro de certos limites, como diz Lima, a autonomia é a possibilidade de aumentar a eficácia de execução periférica das decisões políticas centrais e, ao mesmo tempo, pulverizar e fragmentar possíveis conflitos de alcance global. Sem competências devolvidas ou poderes transferidos para as escolas, sem esquemas de descentralização regional ou municipal, torna-se difícil compreender o discurso pretensamente descentralizador e autonómico, "a não ser por um esbatimento dos elementos políticos, democráticos e participativos, a favor das funções técnicas e modernizadoras, bem patente nos normativos [...] as ideias de descentralização, de autonomia e de 
participação na decisão têm por esta via conhecido um protagonismo assinalável nos discursos e nas tomadas de decisão política" mas, onde ocorreram, deixaram ficar claro as suas concepções instrumentais "de tipo gerencial, técnico-implementativo ou desregulador" que despojam a "descentralização e a autonomia de sentido político democrático-participativo e, simultaneamente, as colocam ao serviço de políticas de signo contrário" (Lima, 1999: 67-68). A questão da autonomia das escolas pode ocultar, como nota Afonso (2002: 81), outras dimensões políticas e ter outras funções latentes, mesmo quando, como acontece no Decreto-Lei 115-A/98, se referem alguns valores que parecem inquestionáveis. Ora vejamos.

A expansão dos projectos de escola, por exemplo, insere-se claramente no processo de alteração dos modelos de gestão das organizações e na necessidade de reorganizar a escola, em nome da promoção do controlo e da qualidade e, também, da necessidade de alargar e dar sentido à participação. Porém, na transposição de um sistema abstracto para um sistema de acção concreto, os projectos concebidos in loco não descolaram do projecto estrutural proposto pela administração e converteramse em meros instrumentos de racionalização das existências (recursos materiais, humanos e financeiros) de acordo com lógicas gerencialistas, executadas pelos operadores. A partir do $2^{\circ}$ regulamento jurídico da autonomia, sobretudo, da variedade de tipos de projectos existentes (Fontoura, 2001; Costa, 1997) foi-se passando para projectos de carácter gerencialista, em quase tudo iguais, sem ambições de carácter reconceptualista ou emancipatório.

Se articularmos as dinâmicas de agrupamento com disposições anteriores (Despacho $\mathrm{n}^{-27 / 97)}$ e posteriores (decretos regulamentares para cada uma das direcções regionais de educação), a propósito da regeneração da administração, percebemos que os agrupamentos constituem um novo locus estratégico que, deliberadamente está a romper com "a centralidade da escola nas políticas educativas, à qual passou a ser atribuído um estatuto ultraperiférico" (Lima, 2004: 42). No caso dos agrupamentos de escola, é claro que o processo de outorga de maior autonomia às escolas veio a "desembocar em "alienação" por parte destas de alguma da autonomia de que dispõem em favor de uma superestrutura que, situada na dependência directa da Administração central desconcentrada, aproxima o controlo desta 
sobre aquelas, nomeadamente através de órgãos colegiais" (Formosinho, Fernandes, Ferreira e Machado, 2005: 150) reproduzindo, a nível territorial, as tendências uniformizadoras de um sistema centralizado. Segundo Ferreira (2005: 278), após a publicação do "decreto da autonomia", os agentes da administração central, das direcções regionais e dos centros da área educativa, apesar da retórica de "territorialização", "autonomia", "participação" deram corpo a uma "lógica normativista e gerencialista, revelando uma forte intervenção burocrática nos processos de elaboração dos 'regulamentos internos' dos agrupamentos de escolas", colocados numa situação de clara dependência.

Segundo Barroso (2003: 19-20), do ponto de vista formal, o processo de aplicação do Dec.-Lei 115-A/98 conseguiu realizar parte das mudanças de estrutura da gestão que estavam previstas. É possível perceber a promoção e o incremento de um amplo conjunto de medidas políticas e administrativas que, em geral, vão no sentido de alterar os modos de regulação dos poderes públicos no sistema escolar, ou mesmo de os substituir por entidades privadas, em muitos dos domínios que constituíam, até aí, um campo privilegiado da intervenção do Estado. Tais medidas nem sempre tiveram a mesma justificação, na origem estiveram diferentes critérios: umas vezes, critérios técnicos de modernização, desburocratização e combate à "ineficiência" do Estado; outras, imperativos de natureza política, de acordo com projectos neoliberais e neoconservadores, com o fim de "libertar a sociedade civil" do controlo do Estado; mas, também, imperativos de natureza filosófica e cultural e de natureza pedagógica.

Tal como acontece com outras medidas educativas, a inscrição na agenda política da questão da autonomia das escolas públicas não ocorreu à margem das transformações do Estado. É no decurso dessas transformações que o Estado vem impondo e induzindo mudanças na administração dos sistemas educativos e é nesse contexto que essas medidas devem ser analisadas - entre o comando do Estado e uma liderança transformacional, ligada à construção de uma nova ordem.

\section{$O$ reforço da teia institucional}

O discurso da universalidade foi progressivamente substituído pelo da flexibilidade mas, na ausência de uma outra cultura de participação, os 
projectos são convertidos em teias institucionais (dispositivos com capacidade para agregar os actores, conectar as acções e, obviamente, os respectivos resultados) que prendem e neutralizam os actores, em nome do serviço público, da ética profissional e de uma "boa governança", de cariz neo-liberal. $\mathrm{Na}$ maior parte dos casos, tudo se mistura em dispositivos híbridos em resultado da sobreposição de diferentes lógicas e da aplicação das medidas avulsas de inspiração diversa que vão definindo as políticas públicas.

Os projectos, apresentados pelo executivo como instrumentos estratégicos ao serviço da participação dos actores e da construção da autonomia, agarrados a um quadro de interdependências, emergente em regras preexistentes, condicionadoras da relação de uns com os outros, foram também instrumentos de controlo dos actores, o que lhe confere uma clara dimensão institucional. Enquanto instrumentos, simultaneamente técnicos e sociais, que organizam as relações sociais, entre o poder público e os seus destinatários, em função das representações e das significações que transportam os projectos, são verdadeiras instituições, ou seja, convenções sociais, sistemas de símbolos, esquemas cognitivos e modelos morais que fornecem "padrões de significação" e guiam a acção humana (Meyer e Scott, 1992).

A multiplicação dos projectos, ligados a diferentes lugares de decisão (agrupamento, escola, departamento curricular, grupo disciplinar, ciclo de ensino, ano e turma) nem sempre significa eficácia, mas o controlo administrativo é mais eficiente. $E$, se dúvida houver, "quanto à autonomia real das escolas na construção do projecto curricular, tanto os normativos finais da revisão nos ensinos básico e secundário, como os documentos de orientação são elucidativos [...]. [Os termos] são slogans, por vezes carregados de um forte valor publicitário, de pretensas reformas" (Pacheco e Morgado, 2002: 25).

A partir de 1998, os projectos, da responsabilidade, directa ou indirecta, dos directores ou das equipas directivas das escolas, são, essencialmente, instrumentos concebidos para a realização de valores pragmáticos, relacionados com a produção de um resultado articulado, num sistema integrado de decisões e rituais. Inspirados no new public management, os projectos têm-se traduzido em planos de acção estruturados e orientados para um funcionamento da escola mais racional e eficaz, 
especialmente, no que diz respeito à optimização do tempo. Para o efeito, em muitas escolas foram constituídas estruturas logísticas, da responsabilidade e confiança dos directores, para acompanharem e orientarem a gestão dos projectos, conforme os termos e os tempos determinados pela tutela. Às medidas administrativas, legitimadas pelo competência de quem dirige, juntase o ambiente escolar, agora mais dependente do contexto social do que das instalações e dos equipamentos, e aumenta a pressão sobre os profissionais que acabam por se moldar ao contexto social e político e optar por uma espécie de consenso, legitimado colectivamente. Por acção da "instrumentação" desenvolvida pela administração que confere uma maior autonomia aos directores, constata-se a adopção crescente de técnicas gestionárias, importadas do sector privado, que casam as práticas burocráticas com os princípios de mercado, em nome da prestação de um serviço público. Para o efeito, regras, mais ou menos formais, vão designando os actores que participam nas decisões políticas, dispensando uns e definindo o papel e a maneira de como outros se hão-de comportar. A questão não reside na institucionalização de regras para a execução local da política educativa de âmbito nacional, a questão coloca-se no entendimento do que é o serviço público e na prestação a exigir aos actores sociais. Trata-se de saber como é que se está a passar das ideias para a acção.

\section{Síntese e reflexões finais}

A leitura das nossas reflexões finais terá, necessariamente, de ser feita à luz das marcas do período histórico em que nos encontramos: desagregação do Estado moderno e rorganização das velhas e novas capacidades do Estado (Santos, 2001, 2006); forte pressão exercida pelas organizações mundiais, sustentadas pelo Consenso de Washington (Hespanha, 2001) e aumento do impacto estratégico do contexto internacional (Santos, 2006); distinção entre Estado e Sociedade Civil em resultado da luta política moderna (Santos, 2006), entre os interesses e grupos sociais que se definem, tanto a partir de premissas neoliberais como dos protestos e propostas dos novos movimentos sociais; tensões e contradições referenciáveis à reconfiguração do papel do Estado (Antunes, 2001) entre os valores da individualização e da selectividade dos actores, do mercado, da privatização, da acumulação de normas, do desenvolvimento de 
tecnoestruturas e a defesa dos direitos humanos, procurando transformar a ordem existente mediante o alargamento do espaço decisional aos indivíduos e aos grupos ligados à etnicidade, ao género ou à defesa do ambiente, constituídos como grupos alternativos; e, por último, a constituição formal e explícita de um nível de governação supranacional como núcleo das políticas a desenvolver na área da educação e formação (Antunes, 2005). O processo de europeização tem vindo a traduzir-se na constituição de um referencial global europeu, um complexo particular de finalidades estratégicas que, cada vez mais, tem vindo a impor-se como base paradigmática para 0 enquadramento dos actores, organização e regulação das suas interacções.

O Estado português actua como um agente catalizador de energias modernizadoras, incrementando, passo a passo, um conjunto de medidas direccionadas para a revisão das relações - Estado-Sociedade Civil-Mercado - e a recomposição dos espaços de acção, dada a crescente conscientização das limitações da ordem tradicional e da diversidade e amplitude dos problemas sociais a requererem novas focalizações e instrumentos.

No restabelecimento das bases das decisões, a prevalência dos imperativos neoliberais tem vindo a afectar o âmbito e a forma do poder de regulação e a estabilização do campo social fabricando receitas para uma "boa governança". Assim, no cenário educativo, apesar da rejeição de uma autoridade central, unilateral, e dos discursos promotores da passagem dos modelos únicos para combinações diversificadas, a administração continua a requerer a coordenação central, identificando necessidades, definindo objectivos, estratégias e instrumentos, a fim de coordenar os próprios processos e procedimentos, em cada contexto de acção.

Num tempo mais longo, percebe-se que se institucionalizou uma política apostada em remodelar o sistema e as estruturas preexistentes, a fim de as desenvolver ou de as transformar, para as compatibilizar com o referencial europeu e de (re)definir os estatutos. O processo de institucionalização é longo e sinuoso, beneficia da convergência das disposições procedentes de várias instâncias, supranacionais, nacionais e locais. Podemos dizer que foi definido a nível supranacional pela UE, fabricado a nível nacional pelo aparelho político-administrativo e concretizado, a nível local, pela autoridade reforçada dos municípios e dos directores 
escolares, sob o controlo administrativo, que têm vindo a entrar como "estrategas" em áreas tradicionalmente reservadas aos professores. Associando a autonomia à ética profissional e às necessidades da comunidade, a administração central fez dos projectos os fios da teia que permitem "prender" os actores, para estabilizar as formas de acção colectiva e tornar mais previsível o seu comportamento. Os códigos de ética profissional, associados aos instrumentos técnicos e a "sanções" legais, prendem os actores a um quadro de interdependências sócio-profissionais que vão modelando e controlando a acção com a forte implicação dos operadores, directores e estruturas logísticas criadas para o efeito. Com a construção dos quadros de interpretação a um nível supra individual e a selecção crescente dos sujeitos a participar nos órgãos de decisão, a intencionalidade dos actores dilui-se e perde a influência decisiva.

Em suma, com o alongar do tempo de observação e apesar das irregularidades, o panorama descrito mostra que, a partir de princípios gerais, como valorização da comunidade, participação dos actores sociais ou autonomia, os decisores foram actuando, em ordem à articulação dos quatro elementos constitutivos de uma política pública, entendida como paradigma. Assim, a partir de princípios gerais, como a valorização da comunidade local e a desconcentração dos serviços administrativos, procedeu-se, passo a passo, à recomposição das hierarquias, introduziram-se novos níveis de coordenação/autoridade e multiplicaram-se as instâncias e os momentos de regulação e supervisão, tendentes a credibilizar o sector junto da opinião pública. Em nome da participação, adoptaram-se e disseminaram-se os projectos, no pressuposto de assim travar uma gestão burocática e dar voz a um maior número de actores. E, para a legitimação das decisões, os grupos instituídos procuraram o apoio dos peritos e difundiram um universo de benefícios e riscos, promovendo, simultaneamente, a necessidade de confiar no funcionamento dos saberes e das pessoas, a que aliaram indicadores de competência e integridade. O procedimento não é novo, a ciência tem mantido uma imagem de conhecimento fiável, que se difunde em atitudes de respeito pela maior parte das formas de especialização técnica, a par de atitudes mais pragmáticas, baseadas em posições de cepticismo ou reserva (Giddens, 1995). 
Integrando um tempo mais longo, nas nossas análises, para além do impacto provocado por algumas das novas normas jurídicas, é visível o movimento dos actores na implementação de estratégias e metodologias de acção que vão do adiamento à reconversão do legislado, através de ajustamentos sucessivos, e à recolocação dos próprios actores, já munidos de uma nova bateria de elementos cognitivos e instrumentos práticos. A acção pública, imbricada no funcionamento dos sistemas sociais, em contextos de regras que se sobrepõem e articulam, só se revela no contexto do desenvolvimento histórico mas, para que tal aconteça, são necessárias abordagens multilaterais que impliquem o Estado e a Sociedade Civil, já que as políticas educativas estão tão fortemente influenciadas por actores políticos, económicos e sociais, como pela burocracia estatal.

\section{Referências}

AFONSO, Almerindo J. (1998). Políticas Educativas e Avaliação Educacional. Braga: Universidade do Minho.

AFONSO, Almerindo J. (2002). A(s) autonomia(s) da escola na encruzilhada entre o velho e o novo espaço público. In L. Lima e A. J. Afonso, Reforma da Educação Pública. Democratização, Modernização, Neoliberalismo. Porto: Edição Afrontamento.

BARROSO, João (2003). Regulação e desregulação nas políticas educativas: tendências emergentes em estudos de educação comparada. In J. Barroso (Org.), A Escola Pública. Regulação. Desregulação. Privatização. Porto: ASA.

BARROSO, João, Org. (2006). A Regulação das Políticas Públicas de Educação. Espaço, Dinâmicas e Actores. Lisboa: Educa/Unidade de I\&D de Ciências da Educação.

BARROSO, João (1999). A escola entre o local e o global. Perspectivas para o século XXI. O caso de Portugal. In J. Barroso (Org.), A Escola entre o Local e o Global. Perspectivas para o século XXI. Lisboa: EDUCA.

BECK, Ulrich (2000). A reinvenção da política. In U. Beck; A. Giddens \& S. Lash (Orgs.), Modernização Reflexiva. Política, Tradição e Estética no Mundo Moderno. Oeiras: Celta.

BURNS, Tom \& CARSON, Marcus (2003). Configurações de governança pluralistas, neocorporativas e da União Europeia. Padrões de elaboração de políticas e de acção dos lobies numa perspectiva comparada. Sociologia, ㄲo 42 .

COMMAILLE, Jacques (2004). Sociologie de l'action publique. In L. Boussaguet; S. Jacquot \& P. Ravinet (Dir.), Dictionnaire des Politiques Publiques. Paris: SCIENCES PO, pp. 413-420. 
COSTA, Jorge A. (1997). O Projecto Educativo de Escola e as Políticas Educativas Locais. Aveiro: Universidade de Aveiro.

CROZIER, M.; HUNTINGTON, S. \& WATANUKI, J. (1975). The Crisis of Democracy: Report on Governability of Democracies to the Trilateral Commission. N. Y.: New York University Press.

FERREIRA, Fernando I. (2005). Os agrupamentos de escolas: lógicas burocráticas e lógicas de mediação. In J. Formosinho; A. S. Fernandes; F. I. Ferreira \& J. Machado, Administração da Educação. Lógicas Burocráticas e Lógicas de Mediação. Porto: ASA.

FONTOURA, Madalena (2000). Projecto Educativo de Escola: um Desafio à Organização Curricular na Escola. Tese de Doutoramento apresentada na Faculdade de Psicologia e Ciências da Educação da Univesidade de Lisboa.

FONTOURA, Madalena (2001). Projecto educativo de escola: realidade ou ficção? Revista de Educação, vol X, 1, pp.123-137.

FONTOURA, Madalena (2005). Uns e Outros: da Multiculturalidade à Construção da Cidadania. Lisboa: EDUCA.

FONTOURA, Madalena (2006). Do Projecto Educativo de Escola aos Projectos Curriculares. Fundamentos, Processos e Procedimentos. Porto: Porto Editora.

FORMOSINHO, João; FERREIRA, Fernando I. \& MACHADO, Joaquim (2000). Políticas Educativas e Autonomia dos Espaços. Porto: ASA.

FORMOSINHO, João; FERNANDES, António S.; FERREIRA, Fernando I. \& MACHADO, Joaquim (2005). Administração da Educação. Lógicas Burocráticas e Lógicas de Mediação. Porto: ASA.

GIDDENS, Anthony (1995). As Consequências da Modernidade. Oeiras: Celta.

GIDDENS, Anthony (2004). Dualidade da Estrutura. Agência e Estrutura. Oeiras: Celta.

HALL, Peter (1993). Policy paradigms, social learning and the state: the case of economic policy-making in Britain. Comparative Politics, 25 (3), pp. 275-298.

JESSOP, B. (1998). The rise of governance and the risks of failure: the case of economic development. International Science Journal, 155, pp. 29-45.

KOIMAN, Jan Ed. (1993). Modern Governance. Londres: Sage.

LASCOUMES, Pierre \& LE GALÈS, Patrick (2004). L'action publique saisie par ses instruments. In P. Lascoumes \& P. Le Galès (Dir.), Gouverner par les instruments. Paris : SCIENCES PO, pp.11-44.

LASCOUMES, Pierre \& LE GALÈS, Patrick (2004). Instrument. In L. Boussaguet; S. Jacquot \& P. Ravinet (Dir.), Dictionnaire des Politiques Publiques. Paris: SCIENCES PO, pp. 267-275.

LE GALÉS, Patrick (2004). Gouvernance. In L. Boussaguet; S. Jacquot \& P. Ravinet (Dir.), Dictionnaire des Politiques Publiques. Paris: SCIENCES PO, pp. 242249.

LIMA, Licínio (1995). Reformar a administração escolar: a recentração por controlo remoto e a autonomia como delegação política. Revista Portuguesa de Educação, 8(1) pp. 57-71. 
LIMA, Licínio (1999). E depois de 25 de Abril de 1974. Centro(s) e periferia(s) das decisões no governo das escolas. Revista Portuguesa de Educação, 12(1) pp. 57-80.

LIMA, Licínio (2002). Modelos organizacionais de escola: perspectivas analíticas, teorias administrativas e o estudo da acção. In L. Machado \& N. Ferreira (Orgs.), Política e Gestão da Educação: Dois Olhares. Rio de Janeiro: DP\&A.

LIMA, Licínio (2004). O agrupamento de escolas como novo escalão da administração desconcentrada. Revista Portuguesa de Educação, 17(2), pp.7- 47.

LIMA, Licínio e AFONSO, Almerindo J. (2002). Reforma da Educação Pública. Democratização, Modernização, Neoliberalismo. Porto: Edições Afrontamento.

KUHN, Thomas S. (1983). Structure des Révolutions Scientifiques. Paris: Flammarion. MÉNY, Yves \& THOENING, Jean-Claude (1989). Politiques Publiques. Paris: Puf.

MEYER, John \& SCOTT, Richard (1992). Organizational Environments. Ritual and Racionality. Londres: Sage.

MULLER, Pierre (2004). Les Politiques Publiques. Paris: Puf.

MULLER, Pierre \& SUREL, Yves (1998). L'Analyse des Politiques Publiques. Paris: Montchrestien.

NEWMAN, Janet (2005). Enter the transformational leader: network governance and the micro-politics of modernization. Sociology, Vol 39 (4), pp.717-734.

NÓVOA, António (1998). Histoire \& Comparaison. Essais sur l'Education. Lisboa: Educa.

NÓVOA, António (2001). O espaço público da educação: imagens, narrativas e dilemas. In AAVV, Espaços de Educação, Tempos de Formação. Lisboa: Gulbenbenkian, pp. 237-263.

NÓVOA, António (2005). Les états de la politique dans l'espace européen de l'éducation. In M. Lawn \& A. Nóvoa (Coord.), L'Europe Réinventée. Paris : Puf, pp.127-224.

NÓVOA, António \& LAWN, Martin, Eds., (2002). Fabricating Europe. The Formation of an Education Space. Dordrecht: Kluwer Academic Publishers.

PACHECO, José A. Org., (2000). Políticas de Integração Curricular. Porto: Porto Editora.

PACHECO, José A. \& MORGADO, José C. (2002). Construção e Avaliação do Projecto Curricular de Escola. Porto: Porto Editora.

PASQUINO, Gianfranco (2005). Curso de Ciência Política. Cascais: Principia.

REYNAUD, Jean-Daniel (1997). Les Règles du Jeu. L'Action Collective et la Régulation Sociale. Paris: Armand Colin.

SANTOS, Boaventura S. (1994). Pela Mão de Alice: o Social e o Político na Pósmodernidade. Porto: Edições Afrontamento.

SANTOS, Boaventura S. (2001). Os processos de globalização. In B. S. Santos (Org.), Globalização, Fatalidade ou Utopia? Porto: Edições Afrontamento.

SANTOS, Boaventura S. (2006). A Gramática do Tempo: Para uma Nova Cultura Política. Para um Novo Senso Comum. Vol. 4. Porto: Edições Afrontamento. 
SARMENTO, Manuel J. (2000). Lógicas de Acção nas Escolas. Lisboa: IIE/ME.

STOER, Stephen; CORTESÃO, Luiza \& CORREIA, José A., Orgs. (2001). Transnacionalização da Educação. Da Crise da Educação à "Educação" da Crise. Porto : Edições Afrontamento.

STOER, Stephen \& MAGALHÃES, António (2005). A Diferença Somos Nós. A Gestão da Mudança Social e as Políticas Educativas e Sociais. Porto: Edições Afrontamento.

SUREL, Yves (1995). Les politiques publiques comme paradigmes. In A. Faure; G. Pollet \& Ph. Warin (Dir.), La Construction du Sens dans les Politiques Publiques. Débats Autour de la Notion de Référentiel. Paris: L'Harmattan, pp. 125-151.

SUREL, Yves (2004). Approches cognitives. In L. Boussaguet; S. Jacquot \& P. Ravinet (Dir.). Dictionnaire des politiques publiques. Paris: SCIENCES PO, pp. 78-85.

SUREL, Yves (2004). Trois i. In L. Boussaguet; S. Jacquot \& P. Ravinet (Dir.). Dictionnaire des politiques publiques. Paris: SCIENCES PO, pp. 452-459.

VAN HAECHT, Anne (1988). Les politiques educatives, figures exemplaires des politiques publiques?, Education et Sociétés, no 1, pp. 21-46. 


\section{Abstract}

This text provides an overview of the broadened field of the policy analysis with the aim of contributing for the understanding of the process of construction and regulation of public policies. It gives account of the complexity of the process that goes beyond the moment of decision, implying different spaces and a great multiplicity of actors. Our reflection derives from the critical analyses, interrogations and commentaries on the Portuguese educational policy, made by different authors, and from different prisms, in the last decades, on the autonomy of the schools, and the effects observed in the implementation of the measures invoked by that autonomy. Particularly, we will consider projects, considered here as tools to solve problems and create opportunities on the borders between the social and the political. It also represents an opportunity to show the importance of the space and temporal dimension for the construction and analysis of the public policies.

Keywords

Policy analisis; Public action; Public policies; Autonomy of the schools; Projects

POLITIQUE ET ACTION PUBLIQUE. D'UNE RÉGULATION CENTRALE À UNE RÉGULATION MULTIPOLAIRE 


\section{Résumé}

Ce texte se place dans le champ élargi de l'analyse politique, ayant l'intention de contribuer à la compréhension du procès de construction et régulation des politiques publiques, donnant compte de la complexité du procès qui va audelà le moment de la décision, impliquant de différentes instances et une grande multiplicité d'acteurs. II constitue une réflexion, construite à partir des analyses, des interrogations, des commentaires et des critiques qui sont arrivées sur la politique éducative portugaise, dans les dernières décennies, formulées par différents auteurs, de différents prismes, en ce qui concerne l'autonomie des écoles, et des effets observés en l'application des mesures qui l'ont invoquée, particulièrement en ce qui concerne les projets, ici considérés comme des outils pour résoudre les problèmes et créer des possibilités à la frontière entre le social et le politique. II représente aussi une occasion de montrer l'importance de la dimension espace-temporal pour la construction et l'analyse des politiques publiques.

Mots-clé

Analyse politique; Action publique; Politiques publiques; Autonomie des écoles; Projets

Recebido em Janeiro, 2008 Aceite para publicação em Junho, 2008

Toda a correspondência relativa a este artigo deve ser enviada para: Maria Madalena Fontoura, Faculdade de Psicologia e de Ciências da Educação da Universidade de Lisboa, Alameda da Universidade, 1649-013 Lisboa, Portugal.Telef.: 2179436 00; e-mail: mfontoura@fpce.ul.pt 